\title{
Influence of communication, collaboration, and decision- making skills on the efficacy of nurses in conducting neonatal resuscitation
}

\author{
Ika Rizki Anggraini ${ }^{1}$, Kuswantoro Rusca Putra ${ }^{2}$, Setyoadi $^{3}$ \\ ${ }^{1}$ Nursing Department, Faculty of Health Sciences, University of Muhammadiyah Malang, Indonesia \\ ${ }^{2,3}$ Nursing Department of Medical Faculty, Brawijaya University, Indonesia
}

\begin{tabular}{l}
\hline Article Info \\
\hline Article history: \\
Received Jul 18, 2020 \\
Revised Jan 21, 2021 \\
Accepted Mar 5, 2021 \\
\hline
\end{tabular}

Keywords:

Communication skills

Neonatal resuscitation

Nurse

Self-efficacy

Workplace

\begin{abstract}
This study aimed to analyze the influence of communication skill, collaboration, and decision-making upon self-efficacy upon Indonesia nurse's self-efficacy in performing neonatal resuscitation. The research employed analytical descriptive design with cross-sectional study approach. The data were collected using questionnaire. Moreover, the research was carried out in Malang City area with the total of 75 nurses employed at neonatal intensive care unit (NICU) room and perinatology unit. Meanwhile, for data analysis, product moment correlation and linear regression were employed. The presence of influence of communication skill, collaboration, and decision-making upon nurse's self-efficacy in performing neonatal resuscitation can be an inestimable reference for the need of objective evaluation on nurse's capability and reflection on skills they have acquired. Communication skills $\mathrm{p}=0.000 \quad(<0.05)$, collaboration $\mathrm{p}=0.000 \quad(<0.05)$, preparation of results $\mathrm{p}=0.000(<0.05)$ with the effectiveness of nurses in the management of neonatal resuscitation. In addition, multiple linear regression showed communication skills $\mathrm{p}=0.000, \mathrm{~B}=0.253$ was the most dominant factor influencing nurses' self- efficacy when handling neonatal resuscitation in hospitals in Malang City of Indonesia. This study found an association related to communication skill, collaboration, and nurse decision making. Communication skills are the dominant factor influencing the efficacy of nurses in performing neonatal resuscitation care.
\end{abstract}

This is an open access article under the $\underline{C C B Y-S A}$ license.

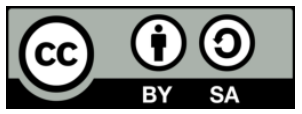

\section{Corresponding Author:}

Ika Rizki Anggraini

Health Science Faculty

Muhammdiyah Malang University

Jl. Bendungan Sutami 188-A, Sumbersari, Kec. Lowokwaru Malang City, East Java, Indonesia

Email: ikarizki@umm.ac.id

\section{INTRODUCTION}

A newborn baby, in between 0-28 days old, is called as neonatal. Neonates are currently in a phase of growth and development of infants who need a few moments in neonates to fall under emergency conditions [1]. For that reason, a neonatal resuscitation action is necessary to perform as immediate and precise as possible to suppress the number of deaths due to treatment delay. According to the data of natal death records, there have been found 35 death cases amongst 1000 live births per year. One of the common neonatal phenomena that frequently occurs is neonatal asphyxia, in which a newborn baby appears to suffer from unspontaneous breathing [2]. The birth process makes neonates negotiate with the new environment. A neonatal resuscitation action is equipped with high complexity to the teams who are responsible for 
the action [3]. Stressful conditions will occur to nurses in the clinic who have the complexity of their actions and clinical environmental factors [4]. Self-efficacy is directly proportional to clinical decision making which is influenced by nursing professionalism [5]. Clinical decision making of child nurses is influenced by nursing professionalism and self-efficacy.

The phenomenon that occurs is that there is still a doubt for the team in the process of handling neonatal resuscitation along with the variety of cases and the complexity of the complex tasks that require self-efficacy to reduce anxiety levels and avoid failed the situation of handling. In the pediatric sphere, patient safety is a challenge for the team in achieving safety because it has vulnerability, vulnerability and vulnerability conditions of growth and development [6]. Thus, self-efficacy is deemed essential in performing a specific action in a workplace [7]. So far, self-efficacy is associated with internal factors in a person. Conceptually, self-efficacy is not only influenced by internal factors but also by external factors [8].

The work environment is one of the external factors that requires a commitment for the team in managing daily challenges in the workplace [9]. The part of ccomponents work environment include communication skills, collaboration, and decision [10]. This phenomenon that occurs in overcoming anxiety and doubt in the handling of neonatal resuscitation can be overcome by increasing a self-efficacy for the team which can be obtained from the work environment which includes communication, collaboration, and decision-making skills. In line with research stating communication skills through training will increase nurses' self-efficacy [11]. Other research suggests that team-based staff skills integrate a work environment that can support successful [12]. Based on the problem, the researcher intended to carry out research at some hospitals in Malang City to investigate the existing influence of communication skill, collaboration, and decision-making upon nurse's self-efficacy in performing neonatal resuscitation.

\section{RESEARCH METHOD}

\subsection{Study design}

Study design was a cross-sectional descriptive survey study. This research was conducted around February 2019 until May 2020. The study was conducted in three hospital with a number of respondents 75 nurses in the NICU room and perinatology with purposive sampling technique with simple random sampling with inclusion criteria: nurses in perinatology unit and the neonatal intensive care unit (NICU) room, have done neonatal resuscitation for junior nurses at least five times and for senior nurses at a minimum 10 times, work experience of at least one year, have done training. Ethical approval was received from the research ethics committee of the Faculty of Medicine, Brawijaya University. All participants provided written informed consent. Privacy and confidentiality were guaranteed.

\subsection{Instrument}

The data were collected using questionnaire in respect of a workplace adopted from association of critical care nurses (AACN, 2005), containing 18 question items along with interval scale from 1-5 namely $1=$ strongly disagree, $2=$ disagree, $3=$ agree, $4=$ quite agree, $5=$ strongly agree. For questionnaire in respect of self-efficacy, resuscitation self-efficacy scale (RSES) ${ }^{7}$ was used, with the total of 17 question items along with interval scale of 1-5 and the descriptors $1-5$, namely $1=$ very not confident, $2=$ not confident, $3=$ confident enough, $4=$ confident, 5=very confident. In addition, validity and reliability tests on the instrument were done by means of Pearson Product Moment $(r)$, showing $r_{\text {count }} \geq r_{\text {table }}$ (sig.0.05) for workplace questionnaire. The questionnaire is reliable; it is proven by Cronbach' Alpha value of 0.750 .

\subsection{Data analysis}

All the data were processed using SPSS Statistics 20.0 with $\mathrm{p}<0.05$ as the significance level. Demographic data on nurses in the form of age, length of work, are presented in the form of mean, standard deviation and gender data, intensity of resuscitation; training is presented in the form of frequency distribution (percentage). Pearson's correlation coefficient is used in the correlation analysis between work environment and nurse's self-efficacy. Multiple linear regression analysis was performed to determine the most dominant work environment variables affecting nurses' self-efficacy in the management of neonatal resuscitation.

\section{RESULTS}

From the result of the analisys the presents demographic caracteristic. Table 1 present of age's most nurses performing neonatal resuscitation was 31 years old, and majority respondent had worked for eight years and under in NICU room or perinatology unit. 
Table 1. The distribution of respondents based on age and working time

\begin{tabular}{cccc}
\hline No & Variabel & Mean \pm Std deviasi & CI 95\% \\
\hline 1 & Age & $31.40 \pm 6.80$ & $29.83-32.97$ \\
2 & Work time & $8.57 \pm 5.95$ & $7.20-9.94$ \\
\hline
\end{tabular}

Table 2 presents the majority of the nurses were female $(98.7 \%)$. Further, referring to resuscitation intensity, there were (24\%) shown 'frequent' to perform resuscitation, while other 'sometimes' in performing the action. Respondents to training program the nurses had once attended, there were (45.3\%). Table 3 shown the results of the statistical relationship has a relationship, direction and strenght of the relationship between communication skill, collaboration, and decision-making upon self-efficacy. It means that the communication skill, collaboration, and decision-making skill was contributed nurse's self-efficacy would be in performing neonatal resuscitation. Table 4 shown statistic regression model a relationship, direction and strenght of the relationship between communication skill, collaboration, and decision-making upon self-efficacy.

Table 2. The distribution of respondents based on sex, resuscitation intensity, and training program

\begin{tabular}{cccc}
\hline No & Characteristics & Frequency (n) & Percentage (\%) \\
\hline 1 & Sex & 1 & 1.3 \\
& Male & 74 & 98.7 \\
& Female & & \\
2 & Resuscitation intensity & & 24 \\
& Frequent & 18 & 76 \\
& Sometimes & 57 & \\
3 & Training program & & 45.3 \\
& Once & 34 & 54.7 \\
\hline
\end{tabular}

Table 3. The relationship of communication skill, collaboration, and decision-making upon self-efficacy

\begin{tabular}{ccc}
\hline Variables & $\mathrm{p}$ & Correlation coefficient \\
\hline Communication & $0.000^{*}$ & 0.666 \\
Collaboration & $0.000^{*}$ & 0.612 \\
Decision making & $0.000^{*}$ & 0.656 \\
\hline *significance on p-value $<0.05$
\end{tabular}

Table 4. Linear regression model

\begin{tabular}{cccccc}
\hline Models & $\mathrm{B}$ & Beta & $\mathrm{R}$ & $\mathrm{R}^{2}$ & $\mathrm{p}$-value \\
\hline Constanta & 13.132 & & 0.881 & 0.776 & 0.000 \\
Communication & 1.038 & 0.253 & & & \\
Collaboration & 0.602 & 0.153 & & & \\
Decision making & 1.157 & 0.251 & & & \\
\hline
\end{tabular}

R-value indicating 0.881 had demonstrated the connection of performing neonatal resuscitation upon communication skill, collaboration, and decision-making the whole result had shown significant (with $\mathrm{p}=0.000 ; \alpha=0.05$ ). The most dominant influence accounting for nurse's self-efficacy in performing neonatal resuscitation was communication skill (with $\beta=0.253$ ).

\section{DISCUSSION}

Communication, collaboration, and decision-making skills in this study are part of a healthy work environment.Communication refers to an open conversation carried out within a team. It was evident that there was found a significant connection between communication skill and nurse's self-efficacy in performing neonatal resuscitation, indicated by a strong connection [13]. These findings indicate that an increase in communication skills is closely related to increased self-efficacy. Communication in this case is carried out by conveying two-way information in a team to decide on a neonatal resuscitation action. Communication skills include conformity between speech and actions taken by the team in handling neonatal resuscitations. The nurse is always in touch with the patient and members of the care team so that effective communication within increase nursing strength profession [14]. The importance of deep communication and interaction nursing is always considered by nurses and nursing scientists as professionals and play an 
important role in based health care team [15]. Effective communication has been widely referred to as key indicators against patient recovery [16]. Data of respondents' characteristics in the research showed that the respondents were averagely 31 years old, which remarked a phase of individual maturity, physically and emotionally [17]. Those who committed such a communication skill were in need of self-trust as regards selfefficacy. Besides, nurse's personality and skill could influence relationship amongst nurses; thus, an effective communication was of necessity. The findings in this study are in line with previous findings which states that a communication skill carried out by training can increase a person's self-efficacy [18].

Collaboration is defined as cooperation committed by team members in carrying out specific and effective treatments to patients [19]. Collaboration need to be mobilized and built by those who are related to the health care system and the numbers are adjusted accordingly resource [20]. Self-efficacy is a part of a thinking process, collaboration committed by nurses amongst the teams encompassed to respect each other based on own competence that raised collective communication and decision-making [21]. In this research, collaboration and self-efficacy were found to have significantly positive connection in the practice of neonatal resuscitation, which means that the better the collaboration was, the higher the self-efficacy would be in performing neonatal resuscitation. The findings in this study are in line with previous findings demonstrated a positive connection between collaboration and self-efficacy amongst nurses working at intensive care unit [22]. Effective collaboration takes place over time if it is done in harmony and makes decisions based on mutual trust, opens communication, and is responsible for improving patient care.

Decision-making was committed based on shared discipline within a team for the sake of fixed joint decision. Self-efficacy contributing to decision-making was influenced by conscience, surrounding support, and the availability of supportive resources [23]. Clinical decision making in nursing practice is a complex, integrated process. The nursing profession which requires a person to have special nurse skills in clinical practice [24]. Decision making is multidimensional and own complexity and requires extensive knowledge, access to untrustworthy information and an enabling environment. Clinical decision making is a nursing one activities that contribute to patient safety, so that quality decision making becomes important in taking [25]. The decisions that nurses make affect patient care, patient safety, and patient outcomes [26]. Decision-making by health professionals can effectively help decide what to do with patients [27]. The findings in this study are related to decision making carried out with the involvement of the team in collecting, filtering and interpreting patient data into information to make decisions about the actions to be taken. The findings in this study are in line with previous findings by [28]that there is a significant relationship between work experience and decision making that can increase one's self-efficacy.

The recent findings indicate there are still some obstacles in implementing a healthy work environment. This is due to several factors such as work experience, characteristics of people, type of education, workload which makes a person not optimal in creating a healthy work environment which includes communication skills, collaboration, and decision making [29]. Communication skills are soft skills that can be done with self-confidence and self-confidence to bring up a behavior [30]. Good communication skills will show an appropriate behavior because communication is a basis for someone in doing something related to interaction with others. Communication needs are the basis of nursing care in monitoring the quality of nursing care so that synergy and a role in the team towards patient care are needed [31]. A good self-belief for someone will make people have self-motivation and behavior [32]. Communication is a thing that can be developed and trained, when an individual is accustomed to doing good communication it will make an increased confidence that ultimately makes a person can try more and have control in behavior the same can be done with collaborative action and decision making. Nurse decision making demands an understanding and understanding of decision making in the environment in an effort to support nursing practice. Effective decision making in an emergency situation needs to pay attention to other factors that influence decision making. Both are things that can be done best through a habitual process and based on the experience a team had in performing neonatal resuscitation procedures [33].

\section{CONCLUSION}

The current research had indicated a significant relationship of communication skill, collaboration, and decision-making upon self-efficacy. In addition, communication skill was found the most dominant factor to influence nurse's self-efficacy in performing neonatal resuscitation.

\section{REFERENCES}

[1] Gilang, H. Notoatmodjo, and M. D. Rakhmawatie, "Factors Associated with the Incidence of Asphyxia Neonatorum (Study at Tugurejo Hospital, Semarang)/Faktor- Faktor Yang Berhubungan Dengan Kejadian Asfiksia Neonatorum (Studi Di RSUD Tugurejo Semarang)," J. Kedokt. Muhammadiyah, no. 2, pp. 11-19, 2010.

[2] A. Alemu, G. Melaku, G. B. Abera, and A. Damte, " $<$ p $>$ Prevalence and associated factors of perinatal asphyxia

The influence of communication, collaboration, and decision-making skills on the... (Ika Rizki Anggraini) 
among newborns in Dilla University referral hospital, Southern Ethiopia- 2017</p >," Pediatr. Heal. Med. Ther., vol. 10, pp. 69-74, 2019, doi: 10.2147/phmt.s196265.

[3] M. W. Abrha, T. T. Asresu, A. A. Araya, and H. G. Weldearegay, "Healthcare Professionals' Knowledge of Neonatal Resuscitation in Ethiopia: Analysis from 2016 National Emergency Obstetric and Newborn Care Survey," Int. J. Pediatr., vol. 2019, pp. 1-7, 2019, doi: 10.1155/2019/8571351.

[4] L. Meng and J. Qi, "The effect of an emotional intelligence intervention on reducing stress and improving communication skills of nursing students," NeuroQuantology, vol. 16, no. 1, pp. 37-42, 2018, doi: 10.14704/nq.2018.16.1.1175.

[5] M. Choi and J. Kim, "Relationships Between Clinical Decision-Making Patterns and Self-Efficacy and Nursing Professionalism in Korean Pediatric Nurses," J. Pediatr. Nurs. Nurs. Care Child. Fam., vol. 30, no. 6, pp. e81-e88, Nov. 2015, doi: 10.1016/j.pedn.2015.07.001.

[6] M. F. da Silva, J. C. Anders, P. K. Rocha, A. I. J. de Souza, and V. B. Burciaga, "Communication in Nursing Shift Handover: Pediatric Patient Safety,” Texto Context.-Enferm., vol. 25, no. 3, pp. 1-9, 2016, doi: 10.1590/010407072016003600015.

[7] G. Alessandri, L. Borgogni, W. B. Schaufeli, G. V. Caprara, and C. Consiglio, "From Positive Orientation to Job performance: The Role of Work Engagement and Self-efficacy Beliefs," J. Happiness Stud., vol. 16, no. 3, pp. 767788, 2015, doi: 10.1007/s10902-014-9533-4.

[8] J. R. Bowles, J. Batcheller, J. M. Adams, D. Zimmermann, and S. Pappas, "Nursing's Leadership Role in Advancing Professional Practice/Work Environments as Part of the Quadruple Aim.," Nurs. Adm. Q., vol. 43, no. 2, pp. 157-163, Apr. 2019, doi: 10.1097/NAQ.0000000000000342.

[9] R. Fida, H. K. S. Laschinger, and M. P. Leiter, "The protective role of self-efficacy against workplace incivility and burnout in nursing: A time-lagged study," Health Care Manage. Rev., vol. 43, no. 1, pp. 21-29, 2018, doi: 10.1097/HMR.0000000000000126.

[10] J. A. Connor et al., "Interprofessional use and validation of the AACN Healthy Work Environment Assessment Tool,” Am. J. Crit. Care, vol. 27, no. 5, pp. 363-371, 2018, doi: 10.4037/ajcc2018179.

[11] Mojtaba Fattahi Ardakani, Mohammad Ali Morowati Sharifabad and A. S. A. Mohammad Amin Bahrami, "The effect of communication skills training on the self-efficacy of nurses: a systematic review and meta-analysis study," Bali Med. J., vol. 8, no. 1, pp. 144-152, 2019, doi: 10.15562/bmj.v8i1.1315.

[12] Jean A. C et al., "Interprofessional Use and Validation of the AACN Healthy Work Environment Assessment Tool," Am J Crit Care., vol. 27, no. 5, pp. 363-371, 2018.

[13] D. Bintabara, A. Ernest, and B. Mpondo, "Health facility service availability and readiness to provide basic emergency obstetric and newborn care in a low-resource setting: Evidence from a Tanzania National Survey," BMJ Open, vol. 9, no. 2, pp. 1-10, 2019, doi: 10.1136/bmjopen-2017-020608.

[14] A. Gultekin, A. A. Ozdemir, and F. Budak, "The Effect of Assertiveness Education on Communication Skills Given to Nursing Students," Int. J. Caring Sci., vol. 11, no. 1, pp. 1-395, 2018.

[15] A. Kunju and A. Ahmad, "Being Tactful: Communication Skill Training in Managing Challenging Situations for Novice Pediatric Nurses," Challenges Nurs. Educ. Res., no. July, pp. 105-115, 2020, doi: 10.1201/9781003043973-11.

[16] C. Liao, Y. Qin, Y. He, and Y. Guo, "The Nurse-Nurse Collaboration Behavior Scale: Development and psychometric testing,” Int. J. Nurs. Sci., vol. 2, no. 4, pp. 334-339, 2015, doi: 10.1016/j.ijnss.2015.10.005.

[17] J. Kosteniuk et al., "Communication tools and sources of education and information: a national survey of rural and remote nurses," J. Med. Libr. Assoc., vol. 107, no. 4, pp. 538-555, 2019, doi: 10.5195/jmla.2019.632.

[18] J. Chung-Yan Chan and P. Y. Sy, "The relationships among personality, intercultural communication, and cultural self-efficacy in nursing students," J. Nurs. Res., vol. 24, no. 4, p. 286Y290, 2016, doi: 10.1097/jnr.0000000000000157..

[19] T. For, AACN Standards for Establishing and Sustaining Healthy Work Environments, 2nd ed. A Journey to Excellence, 2016.

[20] M. A. Rakhudu, M. Davhana, U. Useh, and M. Rakhudu, "A model of collaboration for the implementation of problem-based learning in nursing education in South Africa," Curationis, vol. 40, no. 1, pp. 1-10, 2013.

[21] M. R. Shirey, "Leadership practices for healthy work environments," Nurs. Manage., vol. 48, no. 5, pp. 42-50, May 2017.

[22] A. Granero, J. M. Blanch, and P. Ochoa, "Labor conditions and the meanings of nursing work in Barcelona.," Rev. Latino-Americana Enferm., vol. 26, pp. 1-8, Jan. 2018, [Online]. Available: http://10.0.6.54/1518-8345.2342.2947.

[23] R. W. Lent, G. W. Ireland, L. T. Penn, T. R. Morris, and R. Sappington, "Sources of self-efficacy and outcome expectations for career exploration and decision-making: A test of the social cognitive model of career selfmanagement," J. Vocat. Behav., vol. 99, pp. 107-117, 2017, doi: 10.1016/j.jvb.2017.01.002.

[24] N. Farčić, I. Barać, R. Lovrić, S. Pačarić, Z. Gvozdanović, and V. Ilakovac, "The influence of self-concept on clinical decision-making in nurses and nursing students: A cross-sectional study," Int. J. Environ. Res. Public Health, vol. 17, no. 9, pp. 1-13, 2020, doi: 10.3390/ijerph17093059.

[25] J. Harbison, "Clinical decision making in nursing: Theoretical perspectives and their relevance to practice," J. $A d v$. Nurs., vol. 35, no. 1, pp. 126-133, 2001, doi: 10.1046/j.1365-2648.2001.01816.x.

[26] M. L. Johansen and J. L. O'Brien, "Decision Making in Nursing Practice: A Concept Analysis," Nurs. Forum, vol. 51, no. 1, pp. 40-48, 2016, doi: 10.1111/nuf.12119.

[27] D. Stacey, M. A. Murray, F. Légaré, D. Sandy, P. Menard, and A. O’Connor, "Decision coaching to support shared decision making: A framework, evidence, and implications for nursing practice, education, and policy," Worldviews Evidence-Based Nurs., vol. 5, no. 1, pp. 25-35, 2008, doi: 10.1111/j.1741-6787.2007.00108.x. 
[28] G. Palareti et al., "Comparison between different D-Dimer cutoff values to assess the individual risk of recurrent venous thromboembolism: Analysis of results obtained in the DULCIS study," Int. J. Lab. Hematol., vol. 38, no. 1, pp. 42-49, 2016, doi: 10.1111/ijlh.12426.

[29] C. Catling, R. Hogan, D. Fox, A. Cummins, M. Kelly, and A. Sheehan, "Simulation workshops with first year midwifery students," Nurse Educ. Pract., vol. 17, pp. 109-115, 2016, doi: 10.1016/j.nepr.2015.12.003.

[30] K. G. Yazew, M. H. Gebrie, and Z. B. Aynalem, "Nurses communication skill and associated factors in Amhara Region Referral Hospitals, Ethiopia, 2019," Research Square, pp. 1-15, 2020, doi: 10.21203/rs.2.23987/v1.

[31] H. J. Braun, P. S. O'Sullivan, M. N. Dusch, S. Antrum, and N. L. Ascher, "Improving interprofessional collaboration: Evaluation of implicit attitudes in the surgeon-nurse relationship," Int. J. Surg., vol. 13, pp. 175-179, 2015, doi: 10.1016/j.ijsu.2014.11.032.

[32] F. Ghadamgahi, F. Zighaimat, A. Ebadi, and A. Houshmand, "Knowledge, attitude and self-efficacy of nursing staffs in hospital infections control," J. Mil. Med., vol. 13, no. 3, pp. 167-172, 2011. 